\title{
COMPORTAMENTO, CRENÇAS E VALORES AMBIENTAIS: UMA ANÁLISE DOS FATORES QUE PODEM INFLUENCIAR ATITUDES PRÓ-AMBIENTAIS DE FUTUROS ADMINISTRADORES
}

Leonardo Victor de Sá Pinheiro

Professor na Universidade Federal do Piauí - UFPI

leonardopinheiro@hotmail.com

Verónica Penãloza

Professora na Universidade Estadual do Ceará - UECE vero.pf@hotmail.com

Danielli Leite Campos Monteiro

Bolsista na Universidade Estadual do Ceará - UECE danielli_c_monteiro@hotmail.com

João Carlos Hipólito Bernardes do Nascimento

Doutorando em Ciências Contábeis pela Universidade Federal do Rio de Janeiro - UFRJ jchbn1@gmail.com

\section{RESUMO}

Este estudo tem como objetivo analisar o relacionamento entre os comportamentos ecológicos, as crenças e os valores ambientais na perspectiva de ação dos estudantes do curso de administração no campo de estudo da conservação do meio ambiente. O conhecimento do comportamento ecológico, das crenças e dos valores ambientais que melhor indicam indivíduos predispostos a transformar o discurso em prática, faz-se importante, pois contribui para uma melhor compreensão de quais fatores podem influenciar a prática próambiental desses estudantes. Esta pesquisa contou com a participação de 146 estudantes do curso de administração de empresas de uma universidade pública localizada em uma região metropolitana do nordeste brasileiro. Os dados da pesquisa foram trabalhados com o auxílio do software Statistical Package for the Social Sciences (SPSS) versão 18.0 por meio dos módulos de estatística descritiva, análise fatorial e regressão binária logística. Constatou-se que o comportamento ecológico de ativismo-consumo, a crença antropocêntrica e o valor ecoaltruísta apresentaram maior predisposição à ação para a preservação ambiental e que pelos fatores identificados, pode-se dar suporte aos educadores de escolas de negócios para estimular práticas em prol do meio ambiente. Também foi identificado que estas relações serviram como uma importante ferramenta para a compreensão do comportamento humano diante da temática ambiental.

Palavras-chave: Comportamento; Educação ambiental; Estudantes.

\section{BEHAVIOR, ENVIRONMENTAL BELIEFS AND VALUES: AN ANALYSIS OF FACTORS THAT MAY INFLUENCE ATTITUDES OF PROACTIVE FUTURE ENVIRONMENTAL MANAGERS}

\begin{abstract}
This research aims to analyze the relationship between ecological behaviors, beliefs, and environmental values in terms of action, from the perspective of business schools students within the study field of environmental conservation. To comprehend the ecological behaviors, beliefs, and environmental values that best indicate predisposed individuals to transform speech into practice, it is important to contribute to a better understanding of which factors may influence pro-environmental practice of these students. The research involved the participation of 146 business administration students of a public university, located in a metropolitan region of northeastern Brazil. The statistical software SPSS, version 18, was employed and the descriptive statistics, factor analysis and binary logistic regression methods were used to analyze the survey data. The findings indicate that the environmental behavior of consumer-activism performance, the anthropocentric belief and value eco-altruism showed greater predisposition to support actions for environmental preservation. Through the factors identified, it provides support to the educators within business schools to stimulate practices in favor of the environment. It was also indentified that these relations can be used as an important tool for understanding human behavior in the face of environmental issues.
\end{abstract}

Key-words: Behavior; Environmental education; Students. 


\section{INTRODUÇÃO}

Ganhando cada vez mais ênfase nas discussões acadêmicas e corporativas, o aumento das informações e pesquisas que abordam a problemática ambiental vem recebendo espaço de significativa relevância em nosso cotidiano. De acordo com Corraliza e Martín (2000), apesar de ser crescente o interesse por estudos que investigam o comportamento do ser humano relacionado a natureza, poucos se dedicam à investigação da complexidade do fenômeno comportamental associado ao meio ambiente.

Para uma melhor compreensão da problemática ambiental, diversos autores (Aragonés \& Amérigo, 2010; Monteiro et al. 2010; López, 2002) acreditam que se faz necessário analisar, primeiramente, o comportamento do ser humano diante da degradação e preservação da natureza. Zelezny e Schultz (2000) acreditam que a problemática ambiental está incontestavelmente relacionada com as questões sociais advindas do comportamento humano, sendo necessário, portanto, ser considerada a mudança de conduta a nível individual e social nas investigações de comportamentos pró-ambientais.

Levando-se em consideração o mundo corporativo, a atenção em relação às questões ambientais requer um novo comportamento dos gestores, para que as empresas deixem de ser causa do problema para fazer parte das soluções. Kruglianskas (1993) acredita que embora a importância do meio ambiente para o desempenho empresarial não seja mais questionada, a gestão ambiental ainda enfrenta diversos desafios, como sua inserção no processo decisório das organizações e a integração adequada à dinâmica empresarial. De acordo com Barbieri (2004), faz-se necessário uma nova postura dos empresários para minimizar os problemas ambientais, inserindo a perspectiva ambiental nos processos decisórios das organizações.

Tendo em vista um maior desenvolvimento de práticas ambientais nas empresas, Paulo e Ferolla (2010) ressaltam a importância da formação de administradores aptos a contribuir efetivamente para o desenvolvimento sustentável. Para esses autores, as Escolas de Administração, ao desempenharem seu papel de formação, devem proporcionar aos futuros gestores uma visão que transcenda o utilitarismo puro e simples e passem a avaliar os benefícios da tomada de decisão em direção à sustentabilidade. Ainda, segundo os autores, ao ocupar cargos estratégicos nas empresas, os administradores influenciam diretamente na criação e implementação de diferentes modelos de gestão.

Gonçalves-Dias et al. (2006) acreditam que vários questionamentos são colocados em relação à efetiva mudança de comportamento dos indivíduos, sobretudo dos jovens, frente a necessidade de rever conceitos e posturas ambientais. "Para alguns, a juventude atual estaria cada vez mais distante do comportamento ambientalmente correto. Já para outros, essa juventude seria o motor das mudanças que se fazem necessárias" (Guiddens, 1997 apud Gonçalves-Dias et al., 2006, p.1).

Apesar da Educação Ambiental (EA) ser lei no Brasil desde 1999, Barbieri (2004) ressalta que os cursos de graduação e pós-graduação em Administração têm encontrado muitas dificuldades em implantá-la conforme estabelece a legislação. De acordo com Gonçalves-Dias (2009), a EA apresenta-se como um elemento indispensável para a transformação da consciência ambiental e para consolidar mudanças de valores e comportamentos.

Baseando-se nessa consolidação de mudanças proporcionada pela EA, esta pesquisa leva em consideração que o conhecimento do comportamento ecológico, das crenças e dos valores ambientais que melhor indicam indivíduos predispostos a transformar o discurso em prática, faz-se importante pelo potencial de contribuir para um melhor direcionamento de quais fatores influenciam as condutas pró-ambientais do indivíduo. A importância de se estudar os alunos do curso de administração deve-se ao fato de estes estarem sendo preparados para atuarem como futuros líderes e gestores de empresas, podendo seus comportamentos influenciarem, de forma significativa, nas decisões que envolvam a temática ambiental nas organizações.

Revista de Gestão Social e Ambiental - RGSA, São Paulo, v. 8, n. 1, p. 89-104, jan./abr., 2014. 
No Brasil, ainda são poucos os estudos que procuram compreender o comportamento ecológico e seus antecedentes (Pato, 2004). A contribuição desta pesquisa torna-se possível a partir do momento em que são entendidas as formas como os fatores estudados se relacionam com a intenção em participar de práticas em defesa do meio ambiente. Diante disso, pretende-se, por meio deste estudo, responder ao seguinte questionamento: Quais os comportamentos ecológicos, crenças e valores ambientais que melhor indicam indivíduos propensos a realizarem ações a favor do meio ambiente? Para responder a essa questão, determinou-se como objetivo geral dessa pesquisa analisar como os comportamentos ecológicos, as crenças e os valores ambientais se relacionam diante da perspectiva de ação dos estudantes do curso de administração frente às práticas de conservação do meio ambiente.

\section{FUNDAMENTAÇÃO TEÓRICA}

A literatura base revisada para fundamentação deste trabalho encontra-se organizada mediante a exploração de três aspectos-chave que contribuirão para a compreensão das análises e discussões dos resultados. Inicialmente, foi realizada a contextualização do comportamento ecológico, seguida dos aspectos principais que permeiam o cenário das crenças ambientais na sociedade atual. $\mathrm{O}$ estudo dos valores humanos no contexto ambiental também foi abordado, tendo em vista poder proporcionar uma maior compreensão da importância dos valores como influenciadores da conduta ambiental. A necessidade de se trabalhar esses conceitos proporciona uma maior maturidade para as bases teóricas e conhecimento das habilidades importantes no âmbito empresarial e acadêmico.

\subsection{Comportamento ecológico}

Sendo entendida como um conjunto de ações intencionais e efetivas em relação à proteção do meio ambiente (Corral-Verdugo, 2001), o comportamento ecológico caracteriza-se por ser um conjunto de condutas que visam à preservação da natureza. Diante disso, ao ser utilizado em seu sentido positivo, o comportamento ecológico passa a significar um modo de agir a favor do meio ambiente, denotando condutas pró-ambientais.

Visando propor um modelo cognitivo de conduta ecológica, López (2002) parte do pressuposto de que os valores fundamentados nas normas sociais e nas necessidades psicológicas são os principais motivos que levam os indivíduos a realizarem ações a favor do meio ambiente. Segundo o autor, os valores e as crenças funcionariam como fonte original do comportamento ecológico, podendo, com isso, originar a estrutura cognitiva que sensibiliza o indivíduo a perceber e manter uma série de preocupações sobre as consequências da degradação ambiental.

No Brasil, ainda são escassos os estudos que procuram compreender o comportamento ecológico e seus antecedentes (Pato, Ros \& Tamayo, 2005). Dessa forma, tendo em vista a inexistência de instrumentos que verificassem o comportamento ecológico diante da realidade brasileira, Pato (2004), baseando-se nos trabalhos desenvolvidos anteriormente por Karp (1996) e Kaiser (1998), elaborou a Escala de Comportamento Ecológico (ECE).

Por meio da ECE, Pato (2004), visando verificar a conduta ecológica de jovens universitários, constatou a existência de quatro dimensões que podiam sugerir a caracterização do comportamento ecológico na realidade socioambiental brasileira. As dimensões encontradas foram denominadas respectivamente como:

- Ativismo-Consumo: refere-se as ações relacionadas à preservação e à conservação do meio ambiente, por meio de participação ativa que envolva outras pessoas ou decisão de compra e uso de produtos considerados nocivos ou não ao meio ambiente.

- Economia de Água e Energia: associado ao uso racional dos recursos naturais, apresentando comportamentos relacionados à economia (ou não desperdício) de água e de energia.

- Limpeza Urbana: comportamento de manutenção dos espaços públicos limpos, associados ao tema do lixo urbano.

Revista de Gestão Social e Ambiental - RGSA, São Paulo, v. 8, n. 1, p. 89-104, jan./abr., 2014. 
- Reciclagem: ações de separação do lixo doméstico conforme seu tipo.

Pesquisas realizadas por Campos e Pol (2010); Pato e Tamayo (2006a) e Pato (2004) identificaram que os itens da ECE relacionados ao consumo se concentravam na mesma dimensão dos itens de ativismo. Segundo Pato e Tamayo (2006a) e Pato (2004), a estreita relação encontrada por esses fatores pode sugerir que, possivelmente, os indivíduos mais jovens não seriam consumidores com poder de compra de produtos. Por outro lado, Pato e Tamayo (2006a), em estudo preliminar de validação do instrumento, configuraram as duas dimensões - ativismo e consumo como fatores distintos, apesar da baixa confiabilidade e variância encontrada. Segundo López (2002), os estudos voltados para a explicação do comportamento ecológico, na maioria das vezes, demonstram relações diretas entre diversas variáveis identificadas como antecedentes, tais como os valores e as atitudes. Por sua vez, as pesquisas realizadas nessa área quase sempre geram uma baixa variância e um reduzido poder explicativo das variáveis utilizadas para a compreensão do comportamento humano (Pato \& Tamayo, 2006a).

Ao investigar as relações existentes entre o comportamento ecológico, as crenças ambientais e os fatores demográficos, Pato, Ros e Tamayo (2005) encontraram que as crenças ecocêntricas mostraram-se preditoras positivas do fator limpeza urbana e economia de água e energia, enquanto as crenças antropocêntricas foram negativamente relacionadas com as manifestações desses comportamentos. Segundo os autores, as crenças ecocêntricas, a idade mais avançada e o pertencimento a uma Organização Não-Governamental (ONG) são fatores que contribuem para a expressão de ações ecológicas.

Propondo-se a investigar as relações existentes entre os valores pessoais e o comportamento ecológico de jovens universitários, Karp (1996), utilizando o modelo de valores de Schwartz (1992), constatou que os tipos motivacionais de autotranscendência e abertura a mudança seriam preditores positivos do comportamento ecológico, enquanto os tipos motivacionais de autopromoção e conservação demonstraram-se preditores negativos deste tipo de comportamento.

Campos e Pol (2010) analisaram as diferenças das crenças ambientais e suas relações com o comportamento ecológico de três grupos de trabalhadores brasileiros, sendo estes provenientes de empresas certificadas por Sistema de Gestão Ambiental (SGA), empresas não certificadas e, por último, empresas não certificadas, mas que possuíam uma política ambiental interna. Os autores constataram que tanto as crenças ecocêntricas como as antropocêntricas se associavam positivamente à dimensão de comportamento ecológico voltado para o ativismo e consumo. Quanto ao fator reciclagem, evidenciou-se uma relação inversa das crenças antropocêntricas e este tipo de comportamento. As crenças ecocêntricas, por sua vez, atuaram como preditoras positivas do comportamento de economia de água e energia, bem como também do comportamento ecológico de limpeza urbana.

Em resumo, o comportamento ecológico de ativismo-consumo, destaca-se como influenciador de mudanças de mentalidade e ações, podendo conduzir indivíduos e organizações a um nível de atuação cada vez mais sustentável. Diante disso, é possível verificar que existe um consenso dos autores em relacionar esses comportamentos como direcionadores de atitudes próambientais. A partir dessas discussões, propõe-se a primeira hipótese para esta investigação:

H1 - Indivíduos que apresentam comportamento ecológico de ativismo-consumo possuem maior propensão para realizar condutas pró-ambientais do que os que possuem comportamento de economia de água e energia, limpeza urbana e reciclagem.

\subsection{Crenças ambientais}

Sendo considerado um dos fatores de grande importância para a compreensão do comportamento humano, as investigações sobre as crenças gerais e específicas apresentam diversas contribuições teóricas e práticas. Dunlap e Van Liere (1978), objetivando criar um instrumento que pudesse verificar o novo paradigma existente na população, propuseram a escala do Novo Paradigma Ambiental (NPA). Reformulado e renomeado posteriormente para Novo Paradigma

Revista de Gestão Social e Ambiental - RGSA, São Paulo, v. 8, n. 1, p. 89-104, jan./abr., 2014. 
Ecológico (Dunlap et al., 2000), o instrumento, apesar de bastante utilizado em pesquisas da área ambiental, passou a ser criticado como simplista e de baixo potencial preditor de comportamentos pró-ambientais, o que, segundo Dunlap (2008 apud Campos \& Pol, 2010), deve-se ao fato de o mesmo não ter sido elaborado com a intenção de servir como um preditor de comportamento.

Diante da ausência de um instrumento adequado à realidade brasileira para analisar as crenças ambientais, Pato (2004) desenvolveu a Escala de Crenças Ambientais (ECA). A autora leva em consideração uma estrutura bidimensional, existindo dois tipos de crenças - ecocêntrica e antropocêntrica - que estabelecem uma visão de mundo pró-ambiental, diferenciando-se apenas pelas razões que as motivam. Sendo assim, os indivíduos com crenças ecocêntricas se preocupam com o meio ambiente levando-se em consideração a interdependência entre o homem e a natureza, enquanto os que possuem crenças antropocêntricas valorizam a natureza pelos benefícios que ela oferece ao homem, proporcionando conforto e qualidade de vida. Pode-se observar que ambas expressam consciência ambiental, porém as pessoas com crenças ecocêntricas veem uma dimensão espiritual na natureza e as com crenças antropocêntricas veem os interesses pessoais que dela dependem. De acordo com Pato (2004, p.24):

As crenças ambientais podem indicar, portanto, como as pessoas se relacionam com o meio ambiente e sua predisposição de agirem de maneira mais ou menos ecológica, podendo contribuir para a compreensão do comportamento ecológico e suas diversas formas de manifestação

Dessa forma, a ECA passou a apresentar itens específicos sobre as características naturais e os problemas ambientais enfrentados pelos brasileiros, além de itens gerais sobre a relação do homem com o meio ambiente. López (2002) acredita que os sistemas de crenças ambientais podem ser entendidos como crenças sociais sobre a relação entre o ser humano e o meio ambiente, podendo variar desde uma preocupação antropocêntrica até uma ecocêntrica. A confrontação entre a visão antropocêntrica e ecocêntrica constitui a base de diversas pesquisas (Monteiro et al. 2010; Amérigo et al., 2005, 2007; González \& Amérigo, 1996; Amérigo, González \& Aragonés, 1995; Thompson \& Barton, 1994) acerca das atitudes ambientais. Thompson e Barton (1994) evidenciaram empiricamente que os sujeitos com crenças antropocêntricas também podem demonstrar preocupação com o meio ambiente. Com isso, pensando nos interesses pessoais que a natureza pode lhes proporcionar, esses sujeitos passariam a apresentar um aspecto egoísta de conduta próambiental.

De acordo com Pato (2004), as crenças ambientais podem indicar a predisposição do indivíduo à forma como este se relaciona com o meio ambiente, contribuindo para uma melhor compreensão do comportamento ecológico do ser humano. Diante disso, Pato, Ros e Tamayo (2005, p.8) afirmam que essas crenças "[...]podem indicar o modo em que as pessoas se vinculam com o meio ambiente e sua predisposição de atuar de maneira mais ou menos ecológica".

Ao estudarem as crenças sobre a natureza e as relações entre o ser humano e o meio ambiente, Sanz e Guillén (2005) verificaram que a crença antropocêntrica apresentava uma relação negativa com os valores de harmonia com a natureza e proteção do ambiente, enquanto a crença ecocêntrica, por sua vez, se relacionava de forma positiva com estes valores. Os autores também verificaram a relação das crenças com a obrigação moral de proteger o meio ambiente, sendo evidenciada uma relação negativa com a crença antropocêntrica e positiva com a ecocêntrica e a obrigação moral.

Levando-se em consideração a existência de poucas pesquisas nacionais sobre o tema, SilvaFilho et al. (2010) acreditam ser necessário novos estudos, medidas e análises que abordem as crenças ambientais na sociedade brasileira. Por sua vez, Pato (2004, p. 20) acredita que "[...]apesar de a literatura apontar as crenças ambientais como antecedentes das atitudes e dos comportamentos ecológicos específicos, esse tema ainda se encontra bastante nebuloso e confuso". 
Pato, Ros e Tamayo (2005) afirmam que as crenças ambientais, vistas como um sistema ou visão de mundo, podem ser antecedentes diretos dos comportamentos ecológicos. Esses autores acreditam que as crenças ecocêntricas contribuem para uma expressão positiva de ações a favor do meio ambiente. Em contrapartida, Corral-Verdugo (2001) enfatiza que os indivíduos mesmo possuindo crenças ambientais ecocêntricas, também podem apresentar comportamento contrário a sua tendência, o que pode ser motivado pelas dificuldades de exercer tal ação. Com base nisso, sugere-se a próxima hipótese da pesquisa:

H2 - Indivíduos com crenças ecocêntricas possuem maior propensão para ações de conservação ambiental do que os com crenças antropocêntricas.

\subsection{Valores ambientais}

Apresentando diversas contribuições práticas relacionadas ao comportamento do indivíduo, o estudo dos valores humanos tem sido de grande relevância para a compreensão dos fenômenos sociais, econômicos e ambientais. $\mathrm{O}$ interesse de se pesquisar os valores humanos e sua capacidade explicativa sobre o comportamento do indivíduo não é recente, sendo tratado também como elemento fundamental para compreender a cultura do indivíduo (Campos \& Porto, 2010).

A natureza dos valores humanos tem obtido considerável progresso nos estudos da psicologia, sociologia, filosofia, antropologia e administração, sendo abordada como características individuais estruturais ou "princípios guiadores" que afetam a vida das pessoas em diversos níveis. Segundo Rokeach (1973), os valores humanos são representações cognitivas e transformações das necessidades, que ao serem identificados possibilitam predizer como o sujeito se comportaria em situações diversas. Por sua vez, Sagie e Elizur (1996), acreditam que os valores direcionam as atitudes e os comportamentos das pessoas, podendo estar relacionados a focos específicos da vida do indivíduo, além de formar estruturas inter-relacionadas.

Objetivando propor um instrumento de pesquisa que pudesse mensurar os valores humanos dos indivíduos, Schwartz desenvolveu, em 1992, o Schwartz Values Survey (SVS). O modelo leva em consideração a existência de 57 valores que podem ser organizados em 10 tipos motivacionais que, por sua vez, se referem ao conjunto de valores identificados nas variadas culturas, apresentando uma estrutura dinâmica de similaridade e antagonismo entre eles. De acordo com Tamayo (1994, p. 8), o tipo motivacional seria "[...]um fator composto por diversos valores que apresentam similaridade do ponto de vista do conteúdo motivacional".

A relação estrutural básica entre os valores e entre os tipos motivacionais por eles constituídos pode ser sintetizada por duas dimensões bipolares já verificadas empiricamente tanto no Brasil (Tamayo \& Schwartz, 1993) quanto no exterior (Schwartz, 1992). Tais dimensões, originam pólos denominados de fatores de ordem superior. Os 10 tipos motivacionais são integrados em dois tipos de dimensões antagônicas. A primeira dimensão, "abertura à mudança versus conservação", ordena os valores com base na motivação do indivíduo na independência de ação e pensamento, seguindo seus interesses intelectuais e afetivos, em oposição à tendência a preservar o status quo e a segurança proporcionada pela estabilidade. A segunda dimensão, "autopromoção versus autotranscendência", ordena os valores com base na motivação do indivíduo pela busca do sucesso pessoal, promovendo seus próprios interesses, em oposição a promover o bem-estar dos outros e da natureza (Porto \& Tamayo, 2007; Tamayo, 1994). Diante disso, Porto e Tamayo (2007) acreditam que os tipos motivacionais de segunda ordem representam tanto as relações de congruência dentro de cada agrupamento, quanto também às relações de antagonismo entre eles, conforme pode ser verificado na Figura 1. 


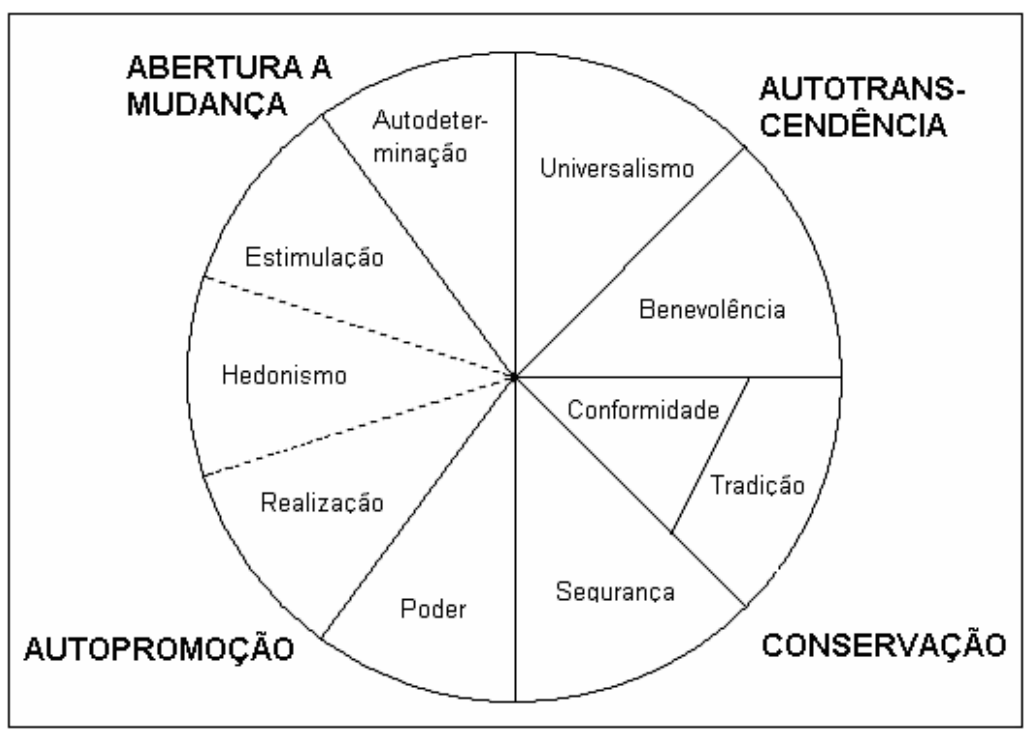

Figura 1. Estrutura dos valores humanos Fonte: Schwartz (1992,)

Recentemente, diversos estudos (López, 2002; Stern et al., 1995; Schultz \& Zelezny, 1998) passaram a associar os valores humanos ao comportamento ambiental. Segundo Corraliza e Martín (2000), a conduta ambiental encontra-se mais relacionada com os valores e as aspirações que orientam a vida do indivíduo do que com a informação específica disponível em relação ao meio ambiente. Baseados nisso, apesar de sua generalidade e subjetividade, os valores possuem significativa influência nas ações que guiam o comportamento ambiental.

Pesquisas realizadas por López (2002); Amérigo e González (2001); Stern et al. (1999) e González e Amérigo (1998) demonstraram relações de condutas pró-ambientais existentes entre 17 valores, sendo 15 extraídos da versão castelhana da Escala de Valores de Schwartz (Schwartz, 1992; Ros \& Grad, 1991) e 2 valores - "Respeito pela Terra" e "Evitar a Contaminação" originados do estudo desenvolvido por Stern et al. (1995). Ao analisar o constructo, López (2002) encontrou a formação de dois fatores, os quais passaram a ser denominados de ecoaltruístas e egocêntricos respectivamente. Os valores ecoaltruístas referem-se a indivíduos preocupados com a natureza e com os demais seres humanos, enquanto os valores egocêntricos estão relacionados com os indivíduos preocupados com os próprios interesses pessoais. Diante disso, tomando-se como base os valores de segunda ordem propostos por Schwartz (1992), os valores ecoaltruístas se enquadrariam na dimensão chamada de autotranscendência e os valores egocêntricos na dimensão denominada de autopromoção (López, 2002).

Conforme o que foi abordado anteriormente, o estudo dos valores humanos pode proporcionar subsídios que facilitam a compreensão do comportamento do indivíduo no meio em que este se encontra inserido. Utiliza-se, portanto, a investigação dos valores na análise pessoal atrelada a um contexto mais amplo, viabilizando o conhecimento do que um indivíduo busca como princípio orientador de sua vida. Diante disso, estabeleceu-se, assim, a próxima hipótese:

H3 - Indivíduos com valores ecoaltruístas possuem maior propensão para agirem a favor do meio ambiente do que os com valores egocêntricos.

\section{MÉTODO DE PESQUISA}

A amostra utilizada é de natureza não-probabilística, por conveniência, participando da pesquisa 146 estudantes do curso de administração de empresas de uma universidade pública localizada em uma região metropolitana do nordeste brasileiro. Foi utilizado como instrumento de pesquisa um questionário estruturado dividido em quatro partes. A primeira apresenta uma escala de Likert de 10 pontos, composta por 29 itens adaptados da escala original desenvolvida por Pato 
(2004). Esta escala propõe a mensuração do comportamento ecológico dos indivíduos, sendo 1 correspondente a nunca e 10 a sempre. Os itens dão formação a quatro fatores denominados: economia de água e de energia, ativismo-consumo, limpeza urbana e reciclagem.

A segunda parte apresenta uma escala composta por 26 itens adaptados da escala original desenvolvida por Pato (2004). As variáveis foram aplicadas por meio de uma escala de Likert de 10 pontos, onde o 1 corresponde a discordo totalmente e 10 a concordo totalmente. As afirmativas mensuram as crenças ambientais, podendo estas serem ecocêntricas ou antropocêntricas em relação ao meio ambiente.

A terceira escala utilizada na pesquisa baseia-se no estudo desenvolvido por Lopez (2002), que utiliza 17 valores relacionados com as condutas pró-ambientais dos indivíduos. A escala utilizada avalia a importância que cada valor possui como princípio de orientação na vida do indivíduo, sendo 1 correspondente a nada importante e 10, a muito importante.

Para avaliar se a preocupação ambiental pode ser traduzida em ação, foi incluída uma pergunta sobre o interesse que o respondente teria em participar de ações voluntárias de preservação do meio ambiente (Coelho et al., 2006). Para validar o real intuito, foi solicitada em seguida a quantidade de horas semanais disponíveis para o trabalho voluntário. Por fim, também foram incluídas questões de natureza demográfica, tais como gênero, idade e estado civil.

Diante do modelo final, procedeu-se a aplicação dos questionários em salas de aula por um pesquisador que dava instruções sobre como respondê-los. Este realizou o mínimo possível de intervenções no processo de aplicação dando apenas explicações quando solicitado, evitando emitir significados diferentes das atribuídas pelos respondentes. Cada respondente gastou, em média, 20 minutos para finalizar o preenchimento do questionário.

Devido à total aleatoriedade dos casos omissos, as não-respostas a determinados itens do questionário - missing values -foram tratadas utilizando o método de substituição pela média dos dados presentes daquela variável. Realizou-se também a recodificação dos itens reversos presentes nas escalas de comportamento ecológico e crenças ambientais, visando deixá-los na mesma direção das outras variáveis.

Os dados foram analisados com o auxílio dos software Statistical Package for the Social Sciences (SPSS) versão 18.0, módulos de estatística descritiva, análise fatorial e regressão binária logística.

\section{RESULTADOS DA PESQUISA}

A análise preliminar dos resultados demonstrou que quanto ao gênero, $52 \%$ dos entrevistados eram do sexo feminino e $48 \%$, do masculino, com idade média de 21 anos, variando estas de 17 a 45 anos. Foi realizada a análise fatorial da escala que mede o comportamento ecológico (Pato, 2004), decidindo-se pela extração de quatro fatores (Cf. Pato \& Tamayo, 2006a, 2006b; Pato, 2004), que explicaram 49,44\% da variância total. A confiabilidade da escala foi verifica por meio do teste de Alpha de Cronbach $(\alpha=0,862)$, mostrando-se bastante satisfatório (Hair Jr. et al., 2005) para estudos exploratórios. Ao retirar as variáveis que apresentaram comunalidades abaixo de 0,4 , a escala passou a ser composta por 26 itens e não mais pelos 29 propostos inicialmente por Pato (2004). 
TABELA 1

Análise Fatorial da Escala de Comportamento Ecológico

\begin{tabular}{|c|c|c|c|c|}
\hline Itens & $\begin{array}{c}\text { Economia de } \\
\text { Água e Energia }\end{array}$ & $\begin{array}{l}\text { Ativismo } \\
\text { Consumo }\end{array}$ & Limpeza & Reciclagem \\
\hline 23 Evito desperdício de energia & ,828 & & & \\
\hline 22 Apago a luz quando saio de ambientes vazios & ,779 & & & \\
\hline 05 Quando estou em casa, deixo as luzes acesas em ambientes que não são usados* & 699 & & & \\
\hline 17 Quando possível economizo água & ,636 & & & \\
\hline 27 Deixo a televisão ligada mesmo sem ninguém assistindo a ela* &, 588 & & & \\
\hline 03 Deixo a torneira aberta durante todo o tempo do banho* &, 582 & & & \\
\hline 18 Colaboro com a preservação da cidade onde vivo** &, 582 & & & \\
\hline 16 Quando estou tomando banho, fecho a torneira para me ensaboar &, 550 & & & \\
\hline 08 Evito desperdício dos recursos naturais &, 537 & & & \\
\hline $\begin{array}{l}24 \text { Quando abro a geladeira já sei o que vou pegar, evitando ficar com a porta } \\
\text { aberta muito tempo, para não gastar energia }\end{array}$ &, 502 & & & \\
\hline $\begin{array}{l}07 \text { Quando tenho vontade de comer alguma coisa que não sei o que é, } \\
\text { abro a geladeira e fico olhando o que tem dentro* }\end{array}$ & ,471 & & & \\
\hline 28 Participo de atividades que cuidam do meio ambiente & & ,688 & & \\
\hline 21 Participo de manifestações públicas para defender o meio ambiente & & 653 & & \\
\hline 10 Evito comprar produtos que são feitos de plástico & & ,613 & & \\
\hline 25 Mobilizo as pessoas nos cuidados necessários para a conservação dos espaços públicos & &, 592 & & \\
\hline 15 Faço trabalho voluntário para um grupo ambiental & &, 583 & & \\
\hline $\begin{array}{l}20 \text { Evito usar produtos fabricados por uma empresa quando sei que essa empresa está poluindo } \\
\text { o meio ambiente }\end{array}$ & &, 530 & & \\
\hline 06 Falo sobre a importância do meio ambiente com as pessoas & &, 530 & & \\
\hline 14 Evito comer alimentos que contenham produtos químicos (conservantes ou agrotóxicos) & & ,499 & & \\
\hline 13 Guardo o papel que não quero mais no bolso, quando não encontro uma lixeira por perto & & & ,780 & \\
\hline 04 Evito jogar papel no chão & & & ,765 & \\
\hline 19 Quando não encontro lixeiras por perto, jogo latas vazias no chão* & & & ,754 & \\
\hline 09 Ajudo a manter as ruas limpas & & & ,609 & \\
\hline 02 Providenciei uma lixeira específica para cada tipo de lixo em minha casa & & & & ,762 \\
\hline 12 Separo o lixo conforme seu tipo & & & &, 542 \\
\hline 01 Jogo todo tipo de lixo em qualquer lixeira* & & & & ,490 \\
\hline
\end{tabular}

Realizou-se a análise de confiabilidade para cada fator encontrado, sendo apresentado juntamente com sua respectiva descrição. De acordo com a TAB.1, o primeiro fator, denominado de economia de água e energia $(\alpha=0,861)$, apresentou uma explicação de $24,58 \%$ da variância total, sendo composto por 11 itens que representam o comportamento de não desperdício de energia $\mathrm{e}$ água. Identificando o comportamento de ativismo-consumo, o segundo fator $(\alpha=0,777)$ foi formado por oito itens que apresentaram uma explicação de 9,79\% da variância total. Esses itens estão relacionados com a participação ativa de conservação e preservação do meio ambiente, bem como a decisão de compra por produtos ecologicamente corretos. Explicando $9,16 \%$ da variância total, o terceiro fator, denominado de limpeza urbana $(\alpha=0,749)$, foi formado por quatro itens que representam o comportamento de conservação de um ambiente público limpo. Por sua vez, o quarto fator, denominado de reciclagem $(\alpha=0,535)$, apresentou uma explicação de $5,90 \%$ da variância total, sendo formado por três itens que se referem aos cuidados de separação dos resíduos conforme seu tipo. Observa-se que os fatores descritos acima apresentaram os mesmos resultados encontrados na pesquisa de Campos e Pol (2010); Pato e Tamayo (2006a, 2006b) e Pato (2004), possibilitando uma confirmação referente a aplicabilidade da escala utilizada.

A análise fatorial da escala que mede as crenças ambientais (Pato, 2004) foi realizada, decidindo-se pela extração de dois fatores (Pato \& Tamayo, 2006a, 2006b; Pato, 2004), que explicaram $31,75 \%$ da variância total. A confiabilidade da escala foi verificada por meio do teste de Alpha de Cronbach $(0,629)$ que, embora tenha sido abaixo do valor considerado como aceitável (0,700), Kline (1999 apud Field, 2009, p.595), afirma que ao "[...]se tratar de construtos psicológicos, valores abaixo de 0,7 podem ser esperados, por causa da diversidade dos construtos que estão sendo medidos". A escala de Pato (2004) é composta por 26 itens, dos quais, após a análise fatorial, foram utilizados os 16 que apresentaram comunalidades acima de 0,4 . 
TABELA 2

Análise Fatorial da Escala de Crenças Ambientais

\begin{tabular}{|c|c|c|}
\hline Itens & Ecocêntrico & Antropocêntrico \\
\hline 23 Os problemas ambientais são conseqüência da vida moderna* &,- 657 & \\
\hline $12 \mathrm{O}$ consumismo agrava os problemas ambientais & ,626 & \\
\hline 24 A interferência dos seres humanos na natureza frequentemente produz conseqüências desastrosas & 621 & \\
\hline 06 A reciclagem contribui para a diminuição dos problemas ambientais gerados pelo uso abusivo de & ,600 & \\
\hline $10 \mathrm{Se}$ as coisas continuarem como estão, vivenciaremos em breve uma catástrofe ecológica & ,477 & \\
\hline $\begin{array}{l}15 \text { Se existissem mais campanhas esclarecendo a população sobre os problemas ambientais, a } \\
\text { situação } \\
\text { brasileira estaria melhor }\end{array}$ & ,446 & \\
\hline 08 Alimentos produzidos organicamente são melhores para a saúde humana & ,438 & \\
\hline 09 A luta dos ambientalistas ajuda a melhorar a nossa qualidade de vida & ,436 & \\
\hline 04 Evitar desperdícios dos recursos naturais deve ser um compromisso de todos nós brasileiros & ,424 & \\
\hline $14 \mathrm{O}$ lixo é responsabilidade apenas do órgão de limpeza urbana* & & ,608 \\
\hline 16 O governo deveria se preocupar mais com os problemas sociais do que com os ambientais* & & ,559 \\
\hline 21 É possível manter o equilíbrio ecológico e ter uma boa qualidade de vida** & &, 551 \\
\hline apenas & & ,493 \\
\hline \multicolumn{3}{|l|}{ pelas ações humanas* } \\
\hline 22 A nossa qualidade de vida depende diretamente dos bens de consumo que possuímos* & & ,493 \\
\hline 26 Separar o lixo conforme o tipo ajuda na preservação do meio ambiente** & & ,492 \\
\hline 17 Os ecologistas estão preocupados demais com as plantas e os animais e se esquecem das pessoas: & & ,490 \\
\hline
\end{tabular}

Como pode ser verificado na TAB.2, as crenças ecocêntricas $(\alpha=0,444)$ foram identificadas no primeiro fator, apresentando uma explicação de $18,85 \%$ da variância total e sendo composta por nove itens. Essas crenças referem-se a pessoas que acreditam no valor da natureza, considerando ser este o principal motivo de preservação. Por sua vez, as crenças antropocêntricas $(\alpha=0,580)$, identificadas no segundo fator, apresentaram uma explicação de 12,89\% da variância total, sendo formada por sete itens. Os indivíduos que apresentam crenças antropocêntricas acreditam no valor da natureza pelos benefícios materiais e físicos que ela pode proporcionar, sendo o interesse pessoal o principal motivo para preservação. Ainda de acordo com a TAB.2, observamos que duas afirmativas agrupadas no fator antropocêntrico contrapor-se-ão à classificação original de Pato (2004) que as identificavam como crenças ecocêntricas.

Ao realizar a análise fatorial da escala, que mede os valores ambientais, decidiu-se pela extração de dois fatores (López, 2002), que explicaram 49,60\% da variância total. A confiabilidade da escala também foi verificada no teste de Alpha de Cronbach $(0,818)$, mostrando-se suficientemente aceitável.

TABELA 3

Análise Fatorial da Escala de Valores Ambientais

\begin{tabular}{|c|c|c|}
\hline Itens & Ecoaltrísta & Egocêntrico \\
\hline 11 RESPEITO PELA TERRA (harmonia com as outras espécies) & ,818 & \\
\hline 01 IGUALDADE (oportunidades iguais para todos) & ,779 & \\
\hline O6 UNIÃO COM A NATUREZA (integração com a natureza) & ,776 & \\
\hline 10 JUSTIÇA SOCIAL (correção da injustiça, cuidado para com os mais fracc & ,751 & \\
\hline 12 PROTETOR DO AMBIENTE (preservar a natureza) & ,714 & \\
\hline O5 UM MUNDO EM PAZ (livre de guerras e conflitos) & ,704 & \\
\hline 17 EVITAR A CONTAMINAÇÃO (conservar os recursos) & ,611 & \\
\hline 14 PRESTATIVO (trabalhar para o bem-estar de outros) &, 528 & \\
\hline 04 RIQUEZAS (posses materiais, dinheiro) & & ,760 \\
\hline 03 UMA VIDA EXCITANTE (experiências estimulantes) & & ,707 \\
\hline O8 AUTORIDADE (direito de liderar ou de mandar) & & ,661 \\
\hline O7 UMA VIDA VARIADA (cheia de desejos, novidades e mudanças) & & ,648 \\
\hline 15 QUE GOZA A VIDA (gostar de comer, sexo, lazer, etc.) & & ,633 \\
\hline 13 INFLUENTE (exercer impacto sobre as pessoas e eventos) & &, 594 \\
\hline 02 PODER SOCIAL (controle sobre os outros, domínio) & & ,586 \\
\hline 16 CURIOSO (ter interesse por tudo, espírito exploratório) & &, 517 \\
\hline
\end{tabular}

Fonte: Dados da pesquisa 
Conforme pode ser analisado na TAB.3, os valores ecoaltruístas $(\alpha=0,862)$, identificados no primeiro fator, foram compostos por oito itens, explicando $29,59 \%$ da variância total. O segundo fator, denominado de egocêntrico $(\alpha=0,814)$, foi formado também por oito itens, explicando $20,01 \%$ da variância total. Procedeu-se a exclusão de apenas um valor, por este ter apresentado comunalidade muito baixa.

Visando verificar se o comportamento ecológico, as crenças e os valores ambientais traduzem-se em ações a favor do meio ambiente, realizou-se a regressão binária logística. A variável predita é a predisposição em participar em um projeto ambiental, que foi estimada pela resposta à questão binária que indagava se o indivíduo tinha ou não disposição para participar de um suposto projeto para o desenvolvimento de ações voluntárias de preservação ambiental. As respostas possíveis eram sim ou não, que foram operacionalizadas como uma variável binária em que o "sim" ficou representado por zero e o "não" por um. As respostas distribuíram-se de maneira disforme, mostrando-se dispostos a participar do projeto apenas $27,3 \%$ dos entrevistados, enquanto $72,7 \%$ destes não manifestaram interesse na ação.

Após a análise fatorial exploratória, cada uma das dimensões fatoriais foi utilizada como variáveis independentes para o teste das hipóteses relacionadas à regressão binária logística.

Os resultados mostrados na TAB. 4, abaixo, indicam que apenas o comportamento ecológico de ativismo-consumo apresenta uma relação estatisticamente significativa (valor $\mathrm{p}<0,05$ ) em relação à intenção em participar de ações a favor do meio ambiente, confirmando, assim, a H1 .

TABELA 4

Coeficientes de regressão binária logistic - ECE

\begin{tabular}{c|c|c|c|c|c}
\hline Dimensão & B & S.E & Wald & Sig. & Exp(B) \\
\hline Economia de Água e Energia &,- 189 &, 209 &, 816 &, 366 &, 828 \\
Ativismo-Consumo &,- 834 &, 242 & 11,912 &, $001 *$ &, 434 \\
Limpeza Urbana &,- 065 &, 214 &, 091 &, 763 &, 937 \\
Reciclagem &,- 256 &, 188 & 1,845 &, 174 &, 774 \\
Constant & 1,052 &, 205 & 26,311 &, 000 & 2,863 \\
\hline
\end{tabular}

Fonte: Dados da pesquisa

Nota: $* \mathrm{p}<0,05$

Nota: $R^{2}=0,314$ (Cox \& Snell), 0,365 (Nagelkerke). Estatística Chi-square de 7,237 com significância de 0,302 no Teste de Hosmer e Lemeshow.

Acerca da análise da qualidade e do desempenho geral do modelo, o Cox \& Snell de 0,314 indica que $31,4 \%$ do Comportamento Ecológico é explicado pelas variáveis independentes pertencentes ao modelo. Já o Nagelkerke de 0,365 indica que a modelagem explica cerca de $37 \%$ das variações ocorridas no Comportamento Ecológico.

A estatística de Hosmer e Lemeshow testa a hipótese nula de que os dados observados são significativamente distintos dos valores previstos pelo modelo, sendo o bom ajuste de modelo indicado pela ocorrência de um valor Qui Quadrado não significante (Field, 2009), assim, o valor de 7,237 e sua significância de 0,302 permitem concluir pela boa capacidade preditiva da modelagem.

Por fim, analisando a estatística Wald, que examina se os coeficientes das variáveis explicativas diferem significativamente de zero, nota-se que a constante e a variável 'Ativismoconsumo' são significantes ao nível de 0,01 e, como tal, contribuem com a previsão da variável de saída (Hair et al., 2005).

A TAB.5 demonstra que a crença ecocêntrica não possui uma relação significativa com o comportamento pró-ambiental, refutando a $\mathrm{H} 2$ (valor p>0,05). Por sua vez, encontrou-se uma relação estatisticamente significativa entre a crença antropocêntrica e a intenção em participar de

Revista de Gestão Social e Ambiental - RGSA, São Paulo, v. 8, n. 1, p. 89-104, jan./abr., 2014. 
ações a favor do meio ambiente, demonstrando que o comportamento pró-ambiental pode ser mais motivado devido aos interesses pessoais em relação à natureza.

TABELA 5

Coeficientes de regressão binária logistic - ECA

\begin{tabular}{c|c|c|c|c|c}
\hline Dimensão & B & S.E & Wald & Sig. & Exp(B) \\
\hline Ecocêntrico &,- 218 &, 203 & 1,162 &, 281 &, 804 \\
Antropocêntrico &,- 542 &, 225 & 5,782 &, $016^{*}$ &, 582 \\
Constant & 1,058 &, 201 & 27,714 &, 000 & 2,881 \\
\hline
\end{tabular}

Fonte: Dados da pesquisa

Nota: $* \mathrm{p}<0,05$

Nota: $R^{2}=0,251$ (Cox \& Snell), 0,365 (Nagelkerke). Estatística Chi-square de 7,448 com significância de 0,282 no Teste de Hosmer e Lemeshow.

Confirmando a $\mathrm{H} 3$, encontrou-se uma relação estatisticamente significativa entre o valor ecoaltruísta e a intenção em participar de ações pró-ambientais, indicando que indivíduos com esses valores possuem maior propensão a agir em defesa do meio ambiente, conforme pode ser observado na TAB. 6 abaixo.

TABELA 6

Coeficientes de regressão binária logistic - EVA

\begin{tabular}{c|c|c|c|c|c}
\hline Dimensão & B & S.E & Wald & Sig. & Exp(B) \\
\hline Ecoaltruísta & $-1,006$ &, 320 & 9,861 &, $002^{*}$ &, 366 \\
Egocêntrico &, 373 &, 219 & 2,905 &, 088 & 1,452 \\
Constant & 1,210 &, 231 & 27,364 &, 000 & 3,355 \\
\hline
\end{tabular}

Fonte: Dados da pesquisa

Nota: $* \mathrm{p}<0,05$

Nota: $R^{2}=0,121$ (Cox \& Snell), 0,175 (Nagelkerke). Estatística Chi-square de 18,365 com significância de 0,127 no Teste de Hosmer e Lemeshow.

\section{CONSIDERAÇÕES FINAIS}

As investigações realizadas demonstraram que o comportamento ecológico de ativismoconsumo relaciona-se, de forma significativa, com a intenção em participar da preservação em defesa do meio ambiente. Diante disso, confirmando os achados da pesquisa realizada por Campos e Pol (2010), ao envolver outras pessoas e possuir decisão de compra e de uso de produtos ecologicamente corretos, o indivíduo pode possuir maior predisposição em participar de ações próambientais.

Verificou-se que os indivíduos que possuem a crença na natureza como importantes devido aos interesses pessoais que esta pode proporcionar ao ser humano apresentaram maior tendência a possuírem comportamentos pró-ambiental. Esse resultado corrobora com a pesquisa realizada por Thompson e Barton (1994) que também evidenciaram que os sujeitos com crenças antropocêntricas podem demonstrar preocupação com o meio ambiente, pensando, no entanto, nos seus interesses pessoais e demonstrando um aspecto egoísta de conduta a favor do meio ambiente.

Por sua vez, constatou-se que os valores ecoaltruístas estão relacionados com a predisposição do indivíduo em participar de ações pró-ambientais. Diante disso, os indivíduos preocupados com a natureza e com os demais seres humanos estariam mais direcionados a agirem a 
favor do meio ambiente do que os que estão preocupados com os próprios interesses pessoais. Ao se tratar de um valor ligado ao tipo motivacional de autotranscendência, o resultado encontrado confirma o estudo realizado por Karp (1996) que constata esse tipo motivacional como preditor positivo do comportamento ecológico.

Respondendo à questão de pesquisa proposta neste estudo, os resultados indicaram que o comportamento ecológico de ativismo-consumo, a crença antropocêntrica e o valor ecoaltruísta estão relacionados de forma significativa com a predisposição dos indivíduos para realizar ações de preservação ambiental. Os conhecimentos apresentados nesta pesquisa podem proporcionar um melhor direcionamento para a educação ambiental das Escolas de Administração, tendo em vista que o comportamento ecológico de ativismo-consumo, a crença antropocêntrica e os valores ecoaltruístas precisam ser mais trabalhados para que esses futuros administradores tenham comportamentos pró-ambientais nas organizações. Diante da temática ambiental, as relações encontradas também podem servir como importante ferramenta para a compreensão do comportamento humano.

Tendo como base os resultados apresentados nesta pesquisa, podem-se traçar estratégias para o ensino, pesquisa, treinamento e conscientização dos futuros administradores acerca da problemática ambiental. Espera-se também que as identificações encontradas permitam um maior entendimento da importância que o nível de consciência ambiental exerce no comportamento dos indivíduos. Os resultados encontrados possibilitam, ainda, compreender a dinâmica existente entre os fatores que podem orientar as condutas ambientais, além de proporcionar um maior suporte empírico para as pesquisas na área.

Como limitação do estudo, cita-se a não utilização de variáveis de controle e a não consideração de outros elementos que também podem influenciar o comportamento ambiental como, por exemplo, a obrigação moral. Apesar de a pesquisa possuir limitações próprias de uma amostra por conveniência, tendo sido desenvolvida somente com estudantes de uma universidade pública de uma região metropolitana do nordeste brasileiro, seus resultados podem não refletir a realidade de outras localidades. Sendo assim, os achados na pesquisa não podem ser generalizados.

Finalmente, os problemas relacionados aos baixos índices de variância extraída das escalas utilizadas indicam como uma boa perspectiva de estudos futuros o aperfeiçoamento do instrumento. Para um maior entendimento das relações evidenciadas nesta pesquisa, torna-se importante a aplicação de outros instrumentos com diferentes amostras formadas por estudantes de outras regiões geográficas, diferentes cursos e instituições de ensino superior. $\mathrm{O}$ uso de métodos qualitativos também possibilitaria maior aprofundamento do tema.

\section{REFERÊNCIAS}

Amérigo, M., Aragonés, J. I., Frutos, B., Sevillano, V., Cortés, B. (2007) Underlying dimensions of ecocentric and antropocentric enviromental beliefs. The Spanish Journal of Psychology, 10 (1), $97-$ 103.

Amérigo, M., Aragónes, J. I., Sevillano, V., Cortés, B. (2005) La estructura de las creencias sobre la problemática medioambiental. Psichotema. 17 (2), 257-262.

Amérigo, M., González, A. (2001) Los valores y las creencias medioambientales en relación con las decisiones sobre dilemas ecológicos. Estudios de Psicología. 22 (1), 65-73.

Amérigo, M., González, A., Aragonés, J.I. (1995) Antropocentrismo versus ecocentrismo en una muestra de estudiantes. Psicología Política, Jurídica y Ambiental. Salamanca: Eudema. 337-344.

Aragonés, J.I., Amérigo, M. (2010) Psicología ambiental. Madrid: Ed. Pirámide. 
Barbieri, J. C. (2004) Educação ambiental e a gestão ambiental em cursos de graduação em administração: objetivos, desafios e propostas. Revista de Administração Pública. 38 (6), 919-946.

Campos, B. C., Pol, E. (2010) As crenças ambientais de trabalhadores provenientes de empresa certificada por SGA podem predizer comportamentos pró-ambientais fora da empresa? Estudos de Psicologia. 15 (2), 208-213.

Campos, C. B., Porto, J,B. (2010) Escala de valores pessoais: validação da versão reduzida em amostra de trabalhadores brasileiros. Psico. 41 (2), 208-213.

Corral-Verdugo, V. (2001) Comportamiento proambiental. Una introducción al estudio de las conductas protectoras del medio ambiente. Santa Cruz de Tenerife, España.: Resma.

Corraliza, J. A., Martin, R. (2000) Estilos de vida, actitudes y comportamientos ambientales. Medio Ambiente y Comportamiento Human. 1 (1), 31-56.

Field, A. (2009) Descobrindo a estatística usando o SPSS. (2. ed.) Porto Alegre: Artmed.

Gonçalves-Dias, S. L. F., Teodósio, A. S. S., Carvalho, S., Silva, H. M. R. (2009) Consciência ambiental: um estudo exploratório sobre suas implicações para o ensino de administração. $R A E$ eletrônica. 8 (1).

Gonçalves-Dias, S. L. F., Teodósio, A. S. S., Silva, H. M. R., Carvalho, S. (2006) A Inserção da Temática Ambiental em Cursos de Administração: Uma Tipologia para (Re) Pensar a Formação de Administradores. Encontro anual da associação nacional de pós-graduação em administração, 30. In: Anais..., Salvador : ANPAD, 2006.

González, A., Amérigo, M. (1998) La preocupación ambiental como función de valores y creencias. Revista de Psicología Social. 13 (3), 453-461.

González, A., Amérigo, M. (1996) Actitudes ambientales e comportamiento ecológico. Ciudad y medio ambiente. Barcelona, 125-129.

Hair, J.F., Aanderson, R. E., Black, W. C., Babin, B. J., Tatham, R. L. (2005) Análise multivariada de dados. Bookman.

Kaiser, F. G. (1998) A general measure of ecological behavior. Journal of Applied Social Psychology. 28 (5), 395-422.

Karp, D. G. (1996) Values and their effect on pro-environmental behavior. Environment and Behavior, 28 (1), 111-133.

Kruglianskas, I. (1993) Ensino da gestão ambiental em escolas de administração de empresas: a experiência da FEA/USP. In: Encontro Nacional de Gestão Empresarial e Meio Ambiente. Anais..., São Paulo: FEA/USP, EAESP/FGV.

López, A. G. (2002) La Preocupación por La calidad del medio ambiente: Un modelo cognitivo sobre la conducta ecológica, 2002. 234f. Tese (Doutorado em Psicologia), Universidade Complutense de Madrid, Espanha. 
Monteiro, D. L. C., Pinheiro, L. V. S., Guerra, D., Peñaloza, V., Freitas, A. A. F. (2010) Motivos e preocupações ambientais na abordagem do estudo da sustentabilidade nos Cursos de Engenharia. In: Encontro Nacional de Engenharia da Produção, 30. Anais... São Carlos/SP.

Paulo, R. R. D., Ferolla, L. M. (2010) Ensaio sobre a educação ambiental na formação de gestores. In: Encontro Nacional de Gestão Empresarial e Meio Ambiente. Anais... São Paulo: FEA/USP.

Pato, C. M. L. (2004) Comportamento ecológico: relações com valores pessoais e crenças ambientais, 2004. 164f. Tese (Doutorado em Psicologia), UnB, Brasília.

Pato, C., Ros, M., Tamayo, A. (2005) Creencias y Comportamiento Ecológico: un estudio empírico con estudiantes brasileños. Medio Ambiente y Comportamiento Humano, 6 (11), 5-22.

Pato, C., Tamayo, A. (2006a) A escala de comportamento ecológico: desenvolvimento e validação de um instrumento de medida. Estudos de Psicologia, 11 (3), 289-296.

(2006b) Valores, creencias ambientales y comportamiento ecológico de activismo. Medio ambiente y comportamiento humano. Editorial Resma, 7 (1), 51-66.

Porto, J. B., Tamayo, A. (2007) Estrutura de valores pessoais: a relação entre valores gerais e laborais. Psicologia: teoria e pesquisa, 23 (1), 63-70.

Rokeach, M. (1973) The nature of human values. New York: Free Press.

Ros, M., Grad, H. M. (1991) El signiflcaclo del valor trabajo como relacionado a la experiencia ocupacional: una comparación ele profesores de EGB y estudiantes del CAP. Revista de Psicología Social, 6 (2), 181-208.

Sagie, A., Elizur, D. (1996) The structure of personal values: a conical representation of múltiple life areas. Journal of organizational behavior, 17 (1), 573-586.

Sanz, L. V., Guillén, C. S. J. (2005) Escala Nuevo Paradigma Ecológico: propriedades psicométricas con una muestra española obtenida a través de internet. Medio Ambiente y Comportamento Humano, 6, 37-49.

Schultz, P. W., Zelezny, L. (1998) Values and proenvironmental behavior. A Five-Country Survey. Journal of Cross-Cultural Psychology, 29 (4), 540-558.

Schwartz, S. H. (1994). Are there universal aspects in the structure and content of human values? Journal of Social Issues, 50, 19-45.

Schwartz, S. H. (1992) Universals in the content and structure of values: Theoretical advances and empirical tests in 20 countries. Em M. P. Zanna (Ed.). Advances in experimental social psychology, $24,1-65$.

Silva-Filho, J. C. L., Neto, F. C. C., Abreu, M. C. S., Cantalice, F. L. B. M., Barbosa Jr, C. D. S. C. (2010) Estudo sobre o Novo Paradigma Ecológico (NPE) no Brasil: medindo a consciência ambiental através da escala (NEP). In: Enanpad, 34. Anais... Rio de Janeiro. 
Stern, P. C., Dietz, T., Abel, T., Guagnano, G. A., Kalof, L. (1999) A value belief norm theory of support for social movements: The case of environmentalism. Human Ecology Review, 6 (2), 8197.

Stern, P. C., Dietz, T., Kalof, L., Guagnano, G. A. (1995) Values, beliefs and proenvironmental action: Attitude formation toward emergent attitude objects. Journal of Applied Social Psychology, 25 (18), 1611-1636.

Tamayo, A. (1994) Hierarquia de valores transculturais e brasileiros. Psicologia: teoria e pesquisa, 10 (2), 269-286.

Tamayo, A., Schwartz, S. H. (1993) Estrutura motivacional dos valores. Psicologia: teoria e pesquisa, 9, 329-348.

Thompson, C. G., Barton, M. A. (1994) Ecocentric and anthropocentric attitudes toward the environment. Journal of Environmental Psychology, 14, 149-157.

Zelezny, L. C., Schultz, P.W. (2000) Promoting environmentalism. Journal of Social Issues, 56 (3), 365-371.

Data da submissão: 16/12/2013

Data da publicação: 30/04/2014 